\title{
Música e seu potencial no ensino de Ciências e SAÚdE
}

\author{
MUSIC AND ITS POTENTIALITY IN SCIENCE AND HEALTH TEACHING
}

DOI: 10.23926/RPD.2526-2149.2020.v5.n2.p944-964.id690

\section{Tainá de Oliveira Flor \\ Mestranda em Ensino em \\ Biociências e Saúde \\ (EBS/IOC/FIOCRUZ). \\ taina.oliveiraflor@gmail.co \\ $\underline{\mathrm{m}}$}

\section{Felipe do Espirito \\ Santo Silva-Pires \\ Doutor em Ensino em \\ Biociências e Saúde \\ (EBS/IOC/FIOCRUZ) \\ Docente na Secretaria de \\ Estado de Educação do Rio \\ de Janeiro (SEEDUC-RJ) \\ felipesilvapires@yahoo.com. $\underline{\mathrm{br}}$}

\section{Valéria da Silva \\ Trajano}

Doutora em Ensino em

Biociências e Saúde

(EBS/IOC/FIOCRUZ)

Docente na Secretaria de

Estado de Educação do Rio

de Janeiro (SEEDUC-RJ)

vlrtrajano@gmail.com
Resumo: $\mathrm{O}$ ensino de Ciências existe no Brasil desde as últimas décadas do século XIX, e mesmo passando por várias mudanças políticas, sociais e educacionais ainda apresenta problemas, como a fragmentação e descontextualização dos conteúdos. Diante dessas dificuldades, as diferentes manifestações artísticas podem contribuir com o processo ensino e aprendizagem, visto que são capazes de integrar saberes diversos e contextualizar conceitos trabalhados em sala de aula. Esta pesquisa analisou como a Música vem sendo aplicada no ensino de Ciências e Saúde, e suas possíveis contribuições para a melhoria desses componentes curriculares. Este estudo é parte de uma Revisão Integrativa sobre arte. Os resultados indicam que a Música vem sendo explorada em todos os níveis de ensino e promove aulas mais participativas, reflexivas e integradoras. Logo, a Música pode facilitar o ensino e aprendizagem por meio da interdisciplinaridade.

Palavras-chave: Música. Ciência e Arte. Ensino de Ciências. Ensino de Saúde. Revisão Integrativa.

\begin{abstract}
Science Education has existed in Brazil since the last decades of the 19th century, and even going through several political, social and educational changes, it still presents problems, such as the fragmentation and decontextualization of contents. Faced with these difficulties, different artistic manifestations can contribute to the teaching and learning process, since they are able to integrate diverse knowledge and contextualize concepts worked in the classroom. This research analyzed how Music has been applied in science and health education, and its possible contributions to the improvement of these curricular components. This study is part of an Integrative Review about Art. The results indicate that Music has been explored at all levels of education and promotes more participatory, reflective and integrative classes. Therefore, Music can facilitate teaching and learning through interdisciplinarity.
\end{abstract}

Keywords: Music. Science and Art. Science Teaching. Health Teaching. Integrative Review. 


\section{INTRODUÇÃO}

O ensino de Ciências no Brasil começou nas escolas secundárias de São Paulo no ano de 1880 (FERREIRA; HARTWING, 2004). As aulas eram baseadas no método tradicional, onde o docente transmitia oralmente informações sobre a temática e os estudantes, por meio de provas e questionários, demonstravam os conhecimentos adquiridos (BRASIL, 1998; KRASILCHIK, 2012). Ao longo do tempo ocorreram diversas mudanças sociais e educacionais e o ensino de Ciências passou por várias modificações. Na década de 1960, no Brasil, houve a criação da Lei de Diretrizes e Bases (LDB) $n^{\circ}$ 4.024/61 que ampliou a carga horária da disciplina de Ciências nas instituições de ensino. Já no início da década de 1970, foi implementada a "pedagogia tecnicista", que deu enfoque à mão de obra especializada e ao ensino profissionalizante, voltado para as necessidades do país. Os estudantes eram preparados para o mercado do trabalho por meio de técnicas de repetições de exercícios e de estratégias de estímulos e de recompensas com descaracterização do ensino de Ciências (BRASIL, 1998; KRASILCHIK, 2012).

Nas décadas subsequentes, essas mudanças modificaram as práticas pedagógicas e o ensino passou a ter como objetivo a formação do "cidadão-trabalhador-estudante". Posteriormente, a reforma curricular, através da publicação dos Parâmetros Curriculares Nacionais (PCN) pelo Ministério da Educação (MEC), em 1998, procurou uma maior contextualização e menor fragmentação dos conteúdos, servindo como base norteadora para o ensino no Brasil (BRASIL, 1998; KRASILCHIK, 2012).

As últimas mudanças ocorreram com a lei $\mathrm{n}^{\circ}$ 13.415, de 2017 que estabeleceu novas mudanças para o ensino médio, aumentando a carga horária e flexibilizando a grade curricular. Foram criadas diversas possibilidades de formação para os discentes, com foco nas áreas de conhecimento e formação técnica e profissional (BRASIL, 2020). Dessa forma, a Lei procurou atender às novas demandas do mundo do trabalho e da vida em sociedade (BRASIL, 1998; KRASILCHIK, 2012).

Apesar de todas essas mudanças, de forma geral, o ensino no Brasil ainda apresenta muitas falhas que levam ao desinteresse pelo ambiente escolar da maioria dos estudantes. Deccache-Maia e Messeder (2016) sugerem que esse fato pode estar associado à forma como os conteúdos são aplicados em sala de aula, pois na maioria das vezes o ensino ainda é conteudista, fragmentado e descontextualizado, dificultando a aprendizagem.

Segundo Theodoro, Costa e Almeida (2015) a aula tradicional prevalece porque as aulas lúdicas requerem métodos diversificados, tempo, espaço e recursos, que não estão disponíveis 
nas escolas na maioria das vezes. O recurso mais utilizado é o livro didático, uma ferramenta de fácil acesso aos estudantes. Tudo isso contribui para um processo de ensino e aprendizagem menos eficiente, promovendo a passividade dos estudantes (THEODORO; COSTA; ALMEIDA, 2015).

Além da falta de recursos didáticos mais atraentes, muitas escolas não oferecem uma alimentação adequada, apresentam superlotação das salas de aula, casos de violência e os docentes não são valorizados tanto financeiramente quanto academicamente. Isso prejudica ainda mais o processo de ensino e aprendizagem (ARAÚJO; JÚNIOR, 2017; LIPPE; BASTOS, 2008).

Esse conjunto de fatores pode estar relacionado à desmotivação dos estudantes em relação ao ambiente escolar. Há décadas alguns estudiosos apontam a necessidade de mudanças nos processos educacionais que transformem o modelo conteudista tradicional em processos que estimulem a participação e a interação dos discentes na busca dos seus conhecimentos (DECCACHE-MAIA; MESSEDER, 2016; DELIZOICOV; ANGOTTI; PERNAMBUCO, 2002; FREIRE, 2014; KRASILCHICK, 2008). Atualmente, esse é um dos desafios do ensino nas diferentes áreas do conhecimento.

Em vista dessas dificuldades, a arte pode ser uma alternativa capaz de auxiliar e de facilitar o processo ensino e aprendizagem, além de incentivar a criatividade dos indivíduos (BARBOSA, 2014; ROOT-BERNSTEIN et al., 2011; SILVA-PIRES et al., 2018). As diferentes manifestações artísticas são capazes de integrar saberes diversos e apresentar os conteúdos de forma clara, prática, prazerosa e objetiva. A partir da inserção da arte, o docente pode tornar suas aulas mais dinâmicas e atrativas, aproximando os conceitos trabalhados em sala de aula com a realidade dos estudantes (SILVA-PIRES et al., 2018).

Em 2010, a Organização das Nações Unidas para Educação, Ciência e Cultura (UNESCO) apresentou um relatório com os desafios da educação na modernidade. Nesse relatório apresenta os quatro pilares da educação do futuro, que são: Aprender a Conhecer, Aprender a Fazer, Aprender a Conviver e Aprender a Ser (DELORS, 2010).

O "Aprender a Conhecer" compreende a construção ativa do conhecimento pelo estudante, o que possibilita o desenvolvimento do senso crítico em relação à realidade na qual o estudante está inserido. O “Aprender a Fazer” se relaciona à formação para o trabalho, devido ao dinamismo do mercado de trabalho na atualidade. Os aprendizes devem ser capazes de trabalhar em equipe, ter boa oratória, facilidade de comunicação, que são quesitos necessários para atender o novo mercado (DELORS, 2010). O pilar “Aprender a Conviver" se baseia nas 
relações com o próximo, em respeitar e viver harmoniosamente em sociedade. Esse é um desafio que tem se tornado cada vez mais difícil, devido à crescente violência em nossa sociedade que se reflete no ambiente escolar (DELORS, 2010; NJAINE; MINAYO, 2003). O “Aprender a Ser" se relaciona ao desenvolvimento total do ser humano, ou seja, envolve tudo que está relacionado ao homem, como por exemplo: "espírito, corpo, inteligência, sensibilidade, sentido estético, responsabilidade pessoal e espiritualidade" (DELORS, 2010). A criatividade se integra nessas características humanas e auxilia nos processos de percepções, de intuições e de emoções. Nesse sentido, a criatividade e a inovação podem ser alcançadas por meio da valorização da utilização da arte no meio educacional (DELORS, 2010; TRAJANO et al., 2018; VILLAÇA, 2014).

A Música está entre as Artes que não encontram definição. Segundo Iazzetta (2001), a Música está presente em várias atividades culturais ao redor do mundo e seu aspecto de abstração impossibilita defini-la. No ensino, a Música poderia auxiliar na memorização dos conteúdos, tornar os estudantes mais participativos, além de unir aspectos cognitivos e lúdicos, atuando como facilitadora do processo de ensinar e aprender (BERTONCELLO; SANTOS, 2002; BRANDÃO; BARROS, 2016). O seu valor no processo educativo foi reconhecido pelo MEC, por meio da Lei $\mathrm{n}^{\circ} 11.769 / 2008$, que tornou a Música conteúdo obrigatório dentro do componente curricular Arte. Ademais, a Lei 13.278/2016 acrescentou a Dança, as Artes Visuais e o Teatro como linguagens artísticas no mesmo componente curricular.

Diante do exposto e das possibilidades da utilização da Arte no ensino, realizamos uma revisão integrativa com o objetivo de analisar como as diferentes manifestações artísticas são utilizadas no ensino de Ciências e Saúde e quais são suas possíveis contribuições tanto na educação básica como no ensino superior. Precisamos realizar um recorte devido ao vasto material encontrado em relação à Música, por isso, neste artigo apresentaremos e discutiremos apenas esses resultados.

\section{Percurso Metodológico}

Esta pesquisa tem um caráter exploratório e descritivo baseado em uma abordagem qualitativa, que visa identificar dados documentais quantitativos e analisá-los à luz de um multirreferencial da área de ensino e Saúde. Para tanto, utilizamos como método para mapear e sintetizar esse conhecimento a revisão integrativa. Segundo Souza, Silva e Carvalho (2010, p. 103-104), “a revisão integrativa determina o conhecimento atual sobre uma temática 
específica, já que é conduzida de modo a identificar, analisar e sintetizar resultados de estudos independentes sobre o mesmo assunto".

A revisão integrativa é uma revisão da literatura que busca analisar trabalhos baseados em diferentes metodologias. O processo é composto pelas seguintes etapas: (i) delimitação de um tema, (ii) determinação de parâmetros de busca na literatura, (iii) caracterização dos artigos encontrados no processo de revisão, (iv) análise e interpretação dos resultados, (v) avaliação crítica dos estudos selecionados, (vi) elaboração da revisão (MENDES; SILVEIRA; GALVÃO, 2008).

Na primeira etapa delimitamos o tema a partir da pergunta: "Como a Arte está sendo desenvolvida no ensino de Ciências e Saúde?", e para responder essa questão buscamos analisar o panorama das publicações que utilizaram Ciência e Arte no ensino de Ciências e Saúde. Optamos por duas combinações de descritores: "Ciência e Arte" + "Ensino de Ciências" e "Ciência e Arte" + "Ensino de Saúde".

Na segunda etapa, no intuito de ampliar as buscas, escolhemos diferentes bancos de dados. As buscas foram realizadas no Google Acadêmico e em bases de dados de publicações indexadas - Biblioteca Virtual em Saúde (BVS), Portal de Periódicos da Coordenação de Aperfeiçoamento de Pessoal de Nível Superior (CAPES) e Scientific Electronic Library Online (SciELO). Optamos por essas plataformas por seu vasto material disponível, além do fácil acesso. A pesquisa considerou artigos científicos e trabalhos completos publicados em anais de congresso nos últimos 12 anos, ou seja, de janeiro de 2008 a janeiro de 2020. Acreditamos que uma década de estudo é um espaço temporal significativo e ao mesmo tempo atual. Cabe ressaltar que livros, resumos, trabalhos de conclusão de curso, dissertações e teses não foram analisadas. Inicialmente, a seleção dos textos se baseou na leitura dos resumos, e aqueles que apresentaram a associação entre Ciência e Arte no ensino de Ciências e Saúde foram lidos na íntegra.

Quanto à etapa três e quatro, construímos uma tabela onde foram preenchidas as informações mais pertinentes de cada trabalho selecionado. Os dados foram adicionados na tabela e analisados de acordo com: título do trabalho, tipo de publicação (artigo ou trabalho completo), ano de publicação, autores, idioma, título do periódico, ensino (particular ou privado), escolaridade (fundamental, médio ou superior), tipo de Arte utilizada, disciplina e base de dados. Nessa etapa, dividimos as Artes considerando suas principais características. Foram incluídos no campo da Música os trabalhos afins, como, por exemplo, análise de letras e construção de paródias. 
$\mathrm{Na}$ quinta etapa, os dados foram avaliados e discutidos de forma crítica, a fim de evidenciar os principais resultados das análises dos artigos e trabalhos completos. A sexta etapa compreendeu a construção da revisão integrativa. Este estudo, como mencionado anteriormente, é um recorte de uma revisão integrativa que buscou analisar como as diferentes formas de Arte estão sendo desenvolvidas no ensino de Ciências e Saúde. Encontramos uma variedade de trabalhos relacionados a Música, por isso, apresentaremos a seguir apenas estes dados.

\section{Resultados E DiscuSsão}

$\mathrm{Na}$ busca realizada com as palavras-chaves "Ciência e Arte" + "Ensino de Saúde" identificamos apenas uma publicação no Google Acadêmico. Ao utilizarmos as palavras-chaves "Ciência e Arte" + "Ensino de Ciências" obtivemos um total 34 publicações, todas a partir do buscador Google Acadêmico. A publicação identificada com as palavras-chaves "Ciência e Arte" + "Ensino de Saúde" também apareceu durante a busca com as palavras-chaves "Ciência e Arte" + "Ensino de Ciências", logo, identificamos um total de 34 publicações diferentes relacionadas à Música nas nossas buscas (quadro 1). Dentre essas publicações, 24 (71\%) eram artigos científicos e 10 (29\%), trabalhos completos publicados em eventos da área de ensino de Ciências.

Quadro 1 - - Publicações encontradas de janeiro de 2008 a janeiro de 2020

\begin{tabular}{|c|c|c|c|c|c|}
\hline \# & Ano & Título da Publicação & Autores & $\begin{array}{c}\text { Área de } \\
\text { concentração } \\
\text { (Escolaridade) }\end{array}$ & $\begin{array}{c}\text { Arte } \\
\text { Utilizada }\end{array}$ \\
\hline 1 & 2008 & $\begin{array}{l}\text { A ciência cantada: um meio de } \\
\text { popularização da ciência e um recurso de } \\
\text { aprendizagem no processo educacional }\end{array}$ & $\begin{array}{l}\text { Oliveira; } \\
\text { Rocha; } \\
\text { Francisco }\end{array}$ & $\begin{array}{l}\text { Ciências e } \\
\text { Biologia (NÃO } \\
\text { CITA) }\end{array}$ & Música \\
\hline 2 & 2009 & $\begin{array}{l}\text { A física na cultura e na pedagogia de } \\
\text { projetos }\end{array}$ & $\begin{array}{l}\text { Queiroz et } \\
\text { al. }\end{array}$ & $\begin{array}{l}\text { Física (EM e } \\
\text { ES) }\end{array}$ & Música \\
\hline 3 & 2010 & $\begin{array}{l}\text { Artes cênicas no ensino de boas práticas } \\
\text { de fabricação: uma prática pedagógica no } \\
\text { curso superior de Química }\end{array}$ & $\begin{array}{l}\text { Mendonça; } \\
\text { Leite }\end{array}$ & Química (ES) & $\begin{array}{l}\text { Quadrinhos, } \\
\text { Música e } \\
\text { Teatro }\end{array}$ \\
\hline 4 & 2010 & $\begin{array}{l}\text { O teatro como ferramenta de } \\
\text { aprendizagem da física e de } \\
\text { problematização da natureza da ciência }\end{array}$ & $\begin{array}{l}\text { Medina; } \\
\text { Braga }\end{array}$ & Física (EM) & $\begin{array}{l}\text { Cinema, } \\
\text { Música e } \\
\text { Teatro } \\
\end{array}$ \\
\hline 5 & 2010 & $\begin{array}{l}\text { Teatro e biologia: uma proposta dinâmica } \\
\text { para compreender a nutrição dos } \\
\text { neurônios e as relações entre os diferentes } \\
\text { sistemas envolvidos }\end{array}$ & $\begin{array}{l}\text { Melo; } \\
\text { Feitoza }\end{array}$ & Biologia (EM) & $\begin{array}{l}\text { Música, } \\
\text { Poesia e } \\
\text { Teatro }\end{array}$ \\
\hline 6 & 2011 & $\begin{array}{l}\text { Extensão universitária interdisciplinar e } \\
\text { contextualizada com a música }\end{array}$ & $\begin{array}{l}\text { Grillo; } \\
\text { Baptista; } \\
\text { Martins }\end{array}$ & $\begin{array}{l}\text { Física (NÃO } \\
\text { CITA) }\end{array}$ & Música \\
\hline
\end{tabular}




\begin{tabular}{|c|c|c|c|c|c|}
\hline 7 & 2011 & $\begin{array}{l}\text { Interação entre música e tecnologia para o } \\
\text { ensino de Biologia: uma experiência } \\
\text { utilizando a web-rádio }\end{array}$ & $\begin{array}{l}\text { Oliveira et } \\
\text { al. }\end{array}$ & Biologia (EM) & Música \\
\hline 8 & 2012 & $\begin{array}{l}\text { Incursões poéticas de Humberto Gessinger } \\
\text { no mundo submicroscópico }\end{array}$ & Mori & $\begin{array}{l}\text { Física e } \\
\text { Química (ES) }\end{array}$ & $\begin{array}{l}\text { Literatura, } \\
\text { Música e } \\
\text { Poesia }\end{array}$ \\
\hline 9 & 2012 & $\begin{array}{l}\text { Rupturas com o ensino tradicional } \\
\text { decorrentes da prática com o ensino de } \\
\text { física através de temas }\end{array}$ & Cruz; Castro & Física (EM) & $\begin{array}{l}\text { Cinema e } \\
\text { Música }\end{array}$ \\
\hline 10 & 2013 & $\begin{array}{l}\text { A música pode ser uma estratégia para o } \\
\text { ensino de ciências naturais? Analisando } \\
\text { concepções de professores da educação } \\
\text { básica }\end{array}$ & $\begin{array}{l}\text { Barros; } \\
\text { Zanella; } \\
\text { Araujo- } \\
\text { Jorge }\end{array}$ & $\begin{array}{l}\text { Ciências } \\
\text { Naturais e } \\
\text { Biologia (PO) }\end{array}$ & Música \\
\hline 11 & 2013 & $\begin{array}{l}\text { Ciência e Arte: uma prosa para a formação } \\
\text { de professores de ciências }\end{array}$ & $\begin{array}{l}\text { Figueira- } \\
\text { Oliveira et } \\
\text { al. }\end{array}$ & Biologia (PO) & $\begin{array}{l}\text { Música e } \\
\text { Imagem }\end{array}$ \\
\hline 12 & 2013 & $\begin{array}{l}\text { Contribuições da epistemologia e da } \\
\text { análise de discurso para o ensino dos } \\
\text { resíduos sólidos }\end{array}$ & Karat & Biologia (EM) & $\begin{array}{l}\text { Cinema e } \\
\text { Música }\end{array}$ \\
\hline 13 & 2014 & $\begin{array}{l}\text { A questão da incomensurabilidade: do } \\
\text { embaraço pitagórico às obras de Leonardo } \\
\text { da Vinci - uma proposta de educação } \\
\text { matemática pela história e pela arte }\end{array}$ & $\begin{array}{l}\text { Chaves; } \\
\text { Rodrigues }\end{array}$ & $\begin{array}{l}\text { Matemática } \\
\text { (EF e EM) }\end{array}$ & $\begin{array}{l}\text { Música e } \\
\text { Pinturas }\end{array}$ \\
\hline 14 & 2014 & $\begin{array}{l}\text { Morando na lua: uma análise semiótica da } \\
\text { interface entre ciência, arte e imaginação } \\
\text { nas aulas de ciências da natureza }\end{array}$ & $\begin{array}{l}\text { Ramos; } \\
\text { Gomes; } \\
\text { Piassi }\end{array}$ & $\begin{array}{l}\text { Ciências da } \\
\text { Natureza (ES) }\end{array}$ & $\begin{array}{l}\text { Cinema, } \\
\text { Literatura e } \\
\text { Música }\end{array}$ \\
\hline 15 & 2014 & $\begin{array}{l}\text { Projeto Água: uma proposta } \\
\text { interdisciplinar }\end{array}$ & Richter & $\begin{array}{l}\text { Ciências } \\
\text { (EF e EM) }\end{array}$ & $\begin{array}{l}\text { Esculturas, } \\
\text { Fotografia e } \\
\text { Música }\end{array}$ \\
\hline 16 & 2015 & $\begin{array}{l}\text { Musicalização, estratégia mnemônica para } \\
\text { a compreensão dos conteúdos de biologia } \\
\text { na EJA }\end{array}$ & $\begin{array}{l}\text { Borges; } \\
\text { Almeida }\end{array}$ & Biologia (EJA) & Música \\
\hline 17 & 2015 & $\begin{array}{l}\text { Música no ensino de ciências: análise da } \\
\text { presença de letras de músicas em livros } \\
\text { didáticos de ciências das séries finais do } \\
\text { ensino fundamental no Brasil }\end{array}$ & $\begin{array}{l}\text { Barros; } \\
\text { Diniz; } \\
\text { Araujo- } \\
\text { Jorge }\end{array}$ & $\begin{array}{l}\text { Ciências } 6^{\circ} \text { ao } \\
9^{\circ} \text { ano }(\mathrm{RB})\end{array}$ & Música \\
\hline 18 & 2016 & $\begin{array}{l}\text { A utilização da música "aqui no mar" } \\
\text { como estratégia pedagógica para o ensino } \\
\text { de ciências e biologia }\end{array}$ & $\begin{array}{l}\text { Brandão; } \\
\text { Barros }\end{array}$ & $\begin{array}{l}\text { Ciências e } \\
\text { Biologia (EF e } \\
\text { EM) }\end{array}$ & $\begin{array}{l}\text { Música e } \\
\text { Poesia }\end{array}$ \\
\hline 19 & 2016 & $\begin{array}{l}\text { Ensinando zoologia a partir da letra da } \\
\text { música "Tico-tico no fubá", de Zequinha } \\
\text { de Abreu }\end{array}$ & $\begin{array}{l}\text { Brandão et } \\
\text { al. }\end{array}$ & $\begin{array}{l}\text { Ciências e } \\
\text { Biologia (EF e } \\
\text { EM) }\end{array}$ & Música \\
\hline 20 & 2016 & $\begin{array}{l}\text { LAMLEC: A Dimensão Lúdica no Ensino } \\
\text { de Ciências }\end{array}$ & $\begin{array}{l}\text { Côrrea; } \\
\text { Vieira; } \\
\text { Velloso }\end{array}$ & $\begin{array}{l}\text { Ciências } 5^{\circ} \text { ano } \\
\text { (EF) }\end{array}$ & $\begin{array}{l}\text { Animação, } \\
\text { Quadrinhos } \\
\text { e Música }\end{array}$ \\
\hline 21 & 2016 & $\begin{array}{l}\text { O ensino de ciências com música nos anos } \\
\text { iniciais numa perspectiva CTS }\end{array}$ & $\begin{array}{l}\text { Cândido; } \\
\text { Deccache- } \\
\text { Maia }\end{array}$ & $\begin{array}{l}\text { Ciências e } \\
\text { física } 2^{\circ} \text { ano } \\
(\mathrm{EF})\end{array}$ & Música \\
\hline 22 & 2017 & $\begin{array}{l}\text { Ciência e Arte na formação inicial de } \\
\text { professores: aspectos educativos e } \\
\text { formativos de uma performance do poema } \\
\text { Física de José Saramago }\end{array}$ & Silva; Silva & Física (ES) & $\begin{array}{l}\text { Literatura e } \\
\text { Performance } \\
\text { (Dança e } \\
\text { Música) }\end{array}$ \\
\hline 23 & 2017 & $\begin{array}{l}\text { Diálogos entre ciência e arte na formação } \\
\text { inicial de professores de física: o processo } \\
\text { de elaboração de uma performance a partir } \\
\text { de um poema }\end{array}$ & Silva; Silva & Física (ES) & $\begin{array}{l}\text { Literatura e } \\
\text { Performance } \\
\text { (Dança e } \\
\text { Música) }\end{array}$ \\
\hline
\end{tabular}




\begin{tabular}{|c|c|c|c|c|c|}
\hline 24 & 2017 & $\begin{array}{l}\text { Expedições por um Brasil sem miséria - } \\
\text { oficinas de ecoarte - um relato de } \\
\text { experiência }\end{array}$ & $\begin{array}{l}\text { Trajano et } \\
\text { al. }\end{array}$ & $\begin{array}{l}\text { Ciências, } \\
\text { Saúde e Meio } \\
\text { Ambiente } \\
\text { (NÃO CITA) }\end{array}$ & $\begin{array}{l}\text { Contação de } \\
\text { histórias, } \\
\text { Cordel, } \\
\text { Fotografia e } \\
\text { Música }\end{array}$ \\
\hline 25 & 2017 & $\begin{array}{l}\text { O uso da música como auxílio no processo } \\
\text { de aprendizagem: um recurso pedagógico }\end{array}$ & $\begin{array}{l}\text { Araújo; } \\
\text { Motta; Lima }\end{array}$ & $\begin{array}{l}\text { Ciências } 6^{\circ} \text { ano } \\
\text { (EF) }\end{array}$ & Música \\
\hline 26 & 2017 & $\begin{array}{l}\text { Pinturas de Salvador Dalí para introduzir } \\
\text { conceitos de Mecânica Quântica no } \\
\text { Ensino Médio }\end{array}$ & $\begin{array}{l}\text { Fernandes et } \\
\text { al. }\end{array}$ & Física (EM) & $\begin{array}{l}\text { Quadrinhos, } \\
\text { Literatura, } \\
\text { Música, } \\
\text { Pintura e } \\
\text { Teatro }\end{array}$ \\
\hline 27 & 2018 & Projeto "Ciência e Arte" & $\begin{array}{l}\text { Rosado; } \\
\text { Gouveia; } \\
\text { Ribeiro }\end{array}$ & $\begin{array}{l}\text { Física, } \\
\text { Química e } \\
\text { Biologia (EM) } \\
\end{array}$ & $\begin{array}{l}\text { Música e } \\
\text { Teatro }\end{array}$ \\
\hline 28 & 2018 & $\begin{array}{l}\text { Química \& Arte: Explorando Caminhos } \\
\text { Criativos em um Projeto com Estudantes } \\
\text { de Ensino Médio }\end{array}$ & Moura & Química (EM) & $\begin{array}{l}\text { Fotografia, } \\
\text { Música, } \\
\text { Pintura e } \\
\text { Poema }\end{array}$ \\
\hline 29 & 2018 & $\begin{array}{l}\text { RITA: Divulgação científica na escola } \\
\text { através de canções do rock }\end{array}$ & $\begin{array}{l}\text { Gomes; } \\
\text { Piassi }\end{array}$ & Ciências (EF) & Música \\
\hline 30 & 2018 & $\begin{array}{l}\text { As relações entre Ciência, Tecnologia e } \\
\text { Sociedade na Arte de Chico Buarque }\end{array}$ & $\begin{array}{l}\text { Camargo; } \\
\text { Camargo; } \\
\text { Silva }\end{array}$ & Ciências (RB) & Música \\
\hline 31 & 2018 & $\begin{array}{l}\text { Sistema nervoso humano: uma proposta } \\
\text { didática para o ensino de biologia }\end{array}$ & $\begin{array}{l}\text { Silva; } \\
\text { Nascimento; } \\
\text { Almeida }\end{array}$ & $\begin{array}{l}\text { Ciências e } \\
\text { Biologia (EM) }\end{array}$ & Música \\
\hline 32 & 2018 & $\begin{array}{l}\text { Trabalhando o conceito de tempo através } \\
\text { do uso de canções com alunos do Ensino } \\
\text { Fundamental II }\end{array}$ & Silva & Ciências (EF) & Música \\
\hline 33 & 2018 & $\begin{array}{l}\text { A psicologia da arte de Vigotski e } \\
\text { algumas notas sobre o químico (e o) } \\
\text { artista }\end{array}$ & Mori & $\begin{array}{l}\text { Ciências (NÃO } \\
\text { CITA) }\end{array}$ & $\begin{array}{l}\text { Música, } \\
\text { Pintura e } \\
\text { Poesia }\end{array}$ \\
\hline 34 & 2019 & $\begin{array}{l}\text { A utilização das paródias "xote chagásico" } \\
\text { e "dengue, zika e chikungunya" como } \\
\text { estratégias de educação em saúde para o } \\
\text { ensino de ciências e biologia }\end{array}$ & $\begin{array}{l}\text { Rodes; } \\
\text { Mesquita; } \\
\text { Barros }\end{array}$ & $\begin{array}{l}\text { Ciências e } \\
\text { Biologia (EM) }\end{array}$ & Música \\
\hline
\end{tabular}

As siglas usadas para identificar a escolaridade foram: EF (Ensino Fundamental), EM (Ensino Médio), ES (Ensino Superior), EJA (Educação de Jovens e Adultos), PO (Pesquisa de Opinião com professores) e RB (Revisão Bibliográfica)

Fonte: Elaborado pelos autores.

Identificamos que há publicações sobre a utilização da Música no ensino de Ciências desde o período inicial da busca, ou seja, 2008. No ano de 2018, houve um pico de oito produções, quando a média de publicações não ultrapassou o total de três artigos no período pesquisado. O motivo dessa produção diferenciada não foi identificado. No ano de 2019 encontramos somente um trabalho relacionado ao ensino de Saúde (Figura 1). 
Figura 1 - - Publicações encontradas no Google Acadêmico, no período de janeiro de 2008 a janeiro de 2020

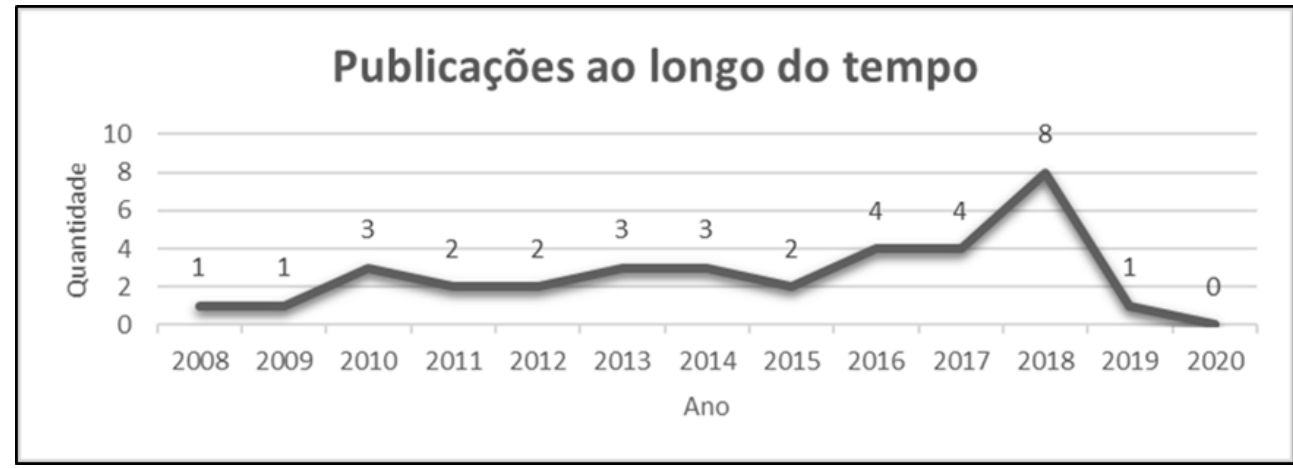

Fonte: Elaborado pelos autores.

Em relação à escolaridade, a Música se fez presente em todos os níveis de ensino: 9 $(26,5 \%)$ das publicações eram voltadas para o ensino fundamental, 16 (47\%), para o ensino médio e $6(17,7 \%)$, para o ensino superior. 2 publicações $(5,9 \%)$ eram direcionadas para a formação de professores, 2 (5,9\%) eram revisões de literatura, que abordavam o tema música, e $4(11,6 \%)$ trabalhos não deixaram evidente o nível de escolaridade proposto em suas atividades (quadro 1). Como determinadas publicações foram utilizadas em diferentes níveis de escolaridade, o somatório dos valores excedeu $100 \%$.

A Música faz parte do contexto escolar desde o seu nascedouro. Na Antiguidade Clássica e na Idade Média, a “matriz escolar” era de livre escolha do educando e era composta pelo Trivium e Quadrívium. O Trivium compreendia a lógica, a gramática e a retórica. O Quadrivium, a geometria, os cálculos, a astronomia e a Música (DURAND, 1991). Com o passar dos anos, a Música e as Artes foram relegadas ao segundo plano e por alguns anos não constaram como obrigatórias na matriz escolar. Contudo, a Arte tornou-se obrigatória há alguns anos, como citado anteriormente, em um ensino fragmentado em disciplinas e ao mesmo tempo descontextualizado. Nesta pesquisa, percebemos que a Música é um recurso que está cada vez mais presente no ambiente escolar. De forma interdisciplinar, aproxima os conteúdos da realidade do educando possibilitando a reflexão, estimulando o aprendizado e tornando o estudante mais participativo e crítico, como declarado na publicação número 25 (quadro 1).

A quantidade expressiva das publicações propostas para o ensino médio pode estar relacionada com a necessidade de tornar as aulas mais atrativas e dinâmicas. $\mathrm{O}$ emprego de metodologias ativas, como sala de aula invertida, metodologia de projetos, Aprendizagem Baseada em Problemas (ABP) podem despertar o interesse do estudante. Nessas metodologias, o protagonismo é do estudante, ou seja, ele é o sujeito ativo do processo de ensino e aprendizagem. Essa responsabilidade pode gerar cidadãos autônomos, criativos e críticos, 
capazes de transformar a realidade ao seu redor (MORÁN, 2015; SILVA, 2015; SIMON et al., 2014).

Diversas publicações com as palavras-chave "Ciência e Arte" + "Ensino de Ciências" abordaram temas relacionados à área da Saúde como prevenção de doenças, preocupações com o lixo, poluição sonora, poluição ambiental e uso de medicamentos. Porém, ao utilizarmos as palavras-chave "Ciência e Arte" + "Ensino de Saúde" identificamos apenas a publicação número 34 (quadro 1). Esse trabalho teve como objetivo criar paródias para auxiliar os discentes na compreensão da doença de Chagas, Dengue, Zika e Chikungunya evidenciando aspectos de extrema importância para a população, principalmente para quem vive em áreas tropicais. Apesar de encontrarmos diversas publicações com conteúdo voltado para a área da Saúde, os autores não utilizaram as palavras "Ensino de Saúde", o que pode ter contribuído para o baixo índice de resultados sobre a temática.

No que se refere ao tipo de pesquisa que compunham as publicações identificadas, verificamos $23(68 \%)$ pesquisas práticas que envolviam a participação ativa de pessoas, e 11 (32\%) pesquisas teóricas. As pesquisas teóricas se relacionam à análise de músicas, revisões de literatura e propostas didáticas. Nas pesquisas práticas, 15 publicações (44\%) foram desenvolvidas em instituições públicas, 1 (3\%), na rede particular de ensino, 2 (6\%) foram realizadas tanto no ensino público como no privado e 5 autores (15\%) não mencionaram o local do desenvolvimento das pesquisas (Quadro 1).

O maior percentual de pesquisas de instituições públicas pode ser devido ao fato dos docentes de rede pública no Brasil possuir maior flexibilidade para cumprirem a matriz curricular, possibilitando a inclusão de atividades lúdicas ao longo do ano letivo. Por outro lado, as escolas privadas impõem aos docentes uma matriz curricular "engessada" com pouco espaço para a pesquisa. Outra circunstância que pode estar relacionada com o alto percentual de publicações de instituições públicas é a existência de diversos programas do governo estadual e federal que visam a integração entre o ensino superior e as escolas públicas. Um deles é o Programa Observatório da Educação (OBEDUC), resultado da parceria realizada entre a CAPES, o Instituto Nacional de Estudos e Pesquisas Educacionais Anísio Teixeira (INEP) e a Secretaria de Educação Continuada, Alfabetização, Diversidade e Inclusão (SECADI). Fundado em 2006, o OBEDUC tem o objetivo de incentivar estudos e pesquisas em educação e promove a articulação entre programas de pós-graduação, escolas da educação básica e as licenciaturas, estimulando, assim, a produção científica (NACARATO, 2016). Outra medida é o Programa Institucional de Bolsas de Iniciação à Docência (PIBID) que busca o 
aperfeiçoamento e a valorização da formação de professores. Esse programa é realizado em parceria com escolas públicas de educação básica e instituições de nível superior que ofertam cursos de licenciatura. O PIBID permite que os licenciandos desenvolvam atividades pedagógicas em parceria com docentes das escolas das redes públicas, favorecendo as publicações de trabalhos na área (NACARATO, 2016).

No que concerne à regionalidade, assim como os três trabalhos práticos, os trabalhos teóricos não mencionaram o local onde a pesquisa foi desenvolvida. Ao analisarmos as demais publicações, percebemos que há uma desigualdade em relação às regiões de origem, já que mais da metade das publicações se concentram na região sudeste do Brasil (Figura 2).

Figura 2 - Relacionado as regiões de onde eram provenientes as publicações identificadas na revisão integrativa

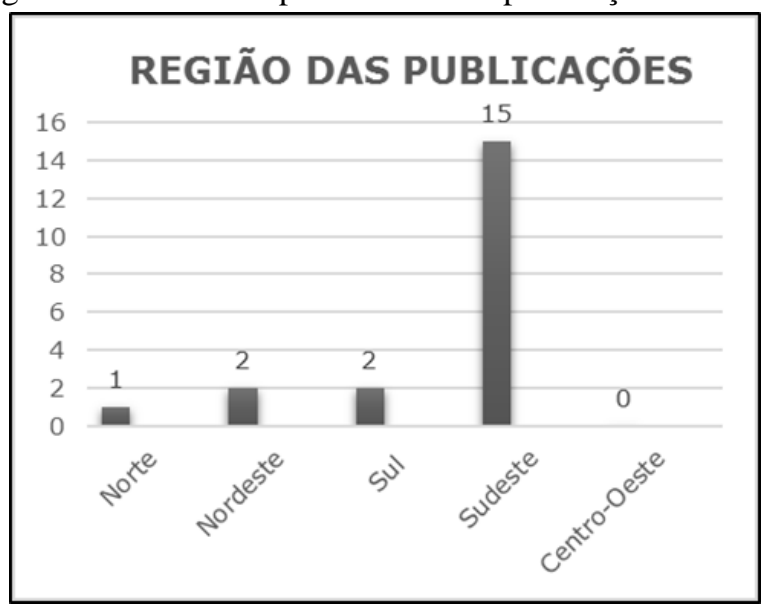

Fonte: Elaborado pelos autores.

O destaque da quantidade da produção científica do Sudeste em relação às demais regiões do país é recorrente em estudos bibliométricos (ALBUQUERQUE et al., 2002; DELIZOICOV; SLONGO; LORENZETTI, 2013; MOREL; MOREL, 1977). Isso ocorre principalmente pela desigualdade de instituições de nível superior, programas de pós-graduação e mão de obra qualificada, que se concentram nessas regiões (TEIXEIRA; MEGID NETO, 2012). O quadro da desigualdade acadêmica é um reflexo da desigualdade socioeconômica brasileira, visto que as assimetrias foram "criadas e acentuadas no bojo do processo de industrialização e de formação/integração do mercado nacional, pelo qual as atividades produtivas se concentraram fortemente nas regiões Sudeste e Sul" (DINIZ; VIEIRA, 2015, p. 108).

Em relação ao componente curricular das 34 publicações analisadas, 17 tratavam de Ciências, 12, de Biologia, 10, de Física, 4, de Química e 1, de Matemática. O total de componentes curriculares citados é maior do que o número de publicações porque alguns 
trabalhos mencionaram mais de uma área de concentração (quadro 1). Nos artigos referentes ao ensino de Ciências e Biologia, a Música estava relacionada aos conteúdos temáticos de Saúde, Meio Ambiente, Sistemas Biológicos, Uso de Medicamentos, Zoologia, Educação Ambiental, Água, Consumo e Poluição. No ensino de Física, os conteúdos comtemplados estavam relacionados à Terra e ao universo, Mecânica Quântica, Energia, Onda, Partícula, Luz, Acústica, Reflexão da Luz e Exploração Espacial. Os conceitos relacionados à Química abordavam as Boas Práticas para a Fabricação, através das quais os discentes aprendiam como minimizar as falhas por falta de padronização no processo de produção, átomos, moléculas e interação entre a Química e a Arte. Já o artigo de Matemática apresentou a Música como números em movimentos, fazendo uma breve comparação entre a Música, a Matemática e as obras de Leonardo Da Vinci.

Alguns autores não explicitaram claramente a sua metodologia, por exemplo, como a Música foi abordada e explorada, assim como não evidenciaram os objetivos a alcançar. Nas publicações números 4 e 5 (quadro 1), os autores apenas informaram que as músicas foram utilizadas durante a apresentação teatral dos discentes. Fato semelhante ocorreu na publicação número 24 (quadro 1), na qual os autores mencionaram a utilização a Música durante uma oficina de ecologia e Arte, mas não apresentaram nem discutiram a obra musical em questão. O artigo número 33 (quadro 1) estabeleceu uma breve relação entre a musicalidade e o ensino. Da mesma forma, o trabalho número 26 (quadro 1) apenas salientou o uso da obra musical "Quanta" de Gilberto Gil para correlacionar com o ensino de Física.

Nesta revisão integrativa, foi possível constatar que grande parte das publicações estavam relacionadas à análise de obras musicais ou à construção de paródias. Entretanto, as publicações números 6 e 21 (quadro 1) evidenciaram o uso da Música para ensinar conceitos musicais como acústica, produção do som, intensidade, duração, frequência e timbre, demonstrando como o som está relacionado com o nosso dia a dia e a sua importância nas relações sociais e afetivas. O interessante é que uma atividade foi desenvolvida no ensino superior e outra com crianças do $2^{\circ}$ ano do ensino fundamental que possuíam idade entre sete e oito anos de idade. Dessa forma, ressalta-se que um dado conteúdo pode ser apresentado de diversas formas para diversas faixas etárias, dependendo apenas de uma adequação da proposta didática.

As publicações números 22 e 23 (quadro 1) utilizaram performances artísticas em um sarau para ilustrar o poema "Física" de José Saramago. O objetivo das autoras era analisar as percepções dos licenciandos em Física sobre a relação entre Ciência e Arte. Os resultados 
obtidos apontaram que a atividade possibilitou uma reflexão formativa, com possibilidades de utilização nas práticas futuras do licenciando. Ressaltamos que durante a análise das publicações notamos que os dois trabalhos, apesar de possuírem títulos diferentes e serem publicadas em eventos científicos diferentes, se referem a uma única atividade, uma vez que a autoria, a metodologia e os resultados são os mesmos em ambas as publicações.

Nossa pesquisa identificou duas revisões da literatura. A publicação número 17 (quadro 1) analisou como a Música é utilizada nos livros didáticos de Ciências do ensino fundamental, revelando que o número de obras musicais presentes nos livros didáticos é baixo, os autores encontraram apenas 32 músicas em mais 6.200 páginas. O trabalho número 25 (quadro 1) evidenciou a união entre a Música e a Ciência, mostrando que a Música pode transformar o ambiente escolar em um lugar prazeroso, investigativo e comprometedor.

Entre os trabalhos analisados, sete publicações se referiam a construção de paródias. Segundo Araújo, Motta e Lima (2017), ao possibilitar a construção de paródias pelos estudantes, o docente permite uma maior interação social, incentivando a busca por objetivos e sonhos. Além disso, a utilização de paródias possibilita que os estudantes utilizem diversos ritmos musicais de sua preferência, passando a melhor conhecer a realidade do outro e apresentam um maior conhecimento sobre o tema ao final da atividade.

A construção de paródias relacionadas com o tema Ciência, tecnologia e sociedade foi encontrada em duas publicações. Ao analisarmos a publicação número 3 (quadro 1), observamos que a docente propôs aos alunos da turma que criassem atividades artísticas relacionadas com tema trabalhado em sala de aula. A partir disso, os discentes se apropriaram do Teatro, das histórias em quadrinhos e da paródia. Apesar dos autores não apresentarem as letras das músicas, ressaltaram que a atividade contribuiu para uma visão crítica além da apropriação dos conteúdos e impactou na formação integral do cidadão, com implicações na Ciência, Tecnologia e Sociedade. O mesmo aconteceu com a publicação número 12 (quadro 1), cuja atividade estava voltada para a percepção sobre resíduos sólidos e seus impactos no meio ambiente. Os estudantes criaram uma paródia, na qual é possível perceber que a atividade promoveu uma reflexão e uma crítica ao consumo desenfreado, como podemos constatar na letra a seguir.

\footnotetext{
Ah, se eu comprasse tudo que eu sonho. Se eu usasse tudo que disponho. Não seria assim tão legal. Ah, se eu tivesse tudo o que eu quis, fosse um pouco mais feliz. Levantasse o meu astral. Inauguração e eu nem fui ver. Aparelhos tão fáceis de entreter. Ah, se eu tivesse fotografado. Se eu tivesse me integrado. Ao meu mundo virtual. Ah, eu compraria o que eu vejo. Lhe deixaria o meu beijo. Na caixa postal. Coisas velhas num mês já ficou pra trás. E eu sou só mais um desses meros tão mortais.
} 
Mas ah, se não fizesse alguma diferença. Se eu pensasse como ela pensa. Com uma vida tão banal. Ah ah ah ou ah, eu compraria pra fazer sorriso. Eu perderia o meu juízo. Só por ser mais atual. Uma promoção, não, eu não fui ver. Aparelhos tão fáceis de se entreter. Coisas velhas num mês que ficou pra trás. E eu sou só mais um desses meros tão mortais. Mas ah, se não fizesse alguma diferença. Se eu pensasse como ela pensa. Com uma vida tão banal. Ah ah ah ou ah, eu compraria pra fazer sorriso. Eu perderia o meu juízo. Só por ser mais atual. Só por ser mais atual (KARAT, 2013, p. 8-9).

Segundo Karat (2013), as atividades que envolvem a construção de paródias são capazes de tornar as pessoas mais criativas e críticas. Snyders (2005, p. 114) corrobora esse pensamento ao dizer que "o aluno não está condenado a ser um simples consumidor da cultura, ele não recebe simplesmente a obra, mas a prolonga, a enriquece, acrescenta-lhe algo [...]”; “[...] o aluno deixa de ser submisso e dominado; ele concilia em si a parcela do sujeito autônomo e a parcela da herança recebida, das influências sofridas, da autoridade".

Já na publicação número 28 (quadro 1) foi proposta aos estudantes a criação de uma obra de teor artístico de livre escolha e sua correlação com o conteúdo de Química. Grande parte dos estudantes criaram desenhos, poemas e paródias, cruzando as fronteiras entre Ciência e Arte. As paródias também fizeram parte dos trabalhos números 27 e 31 (quadro 1), mas em ambos os casos os docentes optaram por trabalhar com paródias prontas. As atividades estimularam o aprendizado e a compreensão do conteúdo. Assim, constatamos que atividades com paródias - sejam construídas pelos alunos, sejam pré-concebidas - se mostraram eficazes para auxiliar o processo de ensino e aprendizagem.

No que diz respeito à publicação número 16 (quadro 1), as paródias permitiram o desenvolvimento de habilidades como criatividade, imaginação, criticidade, sensibilidade e percepção. Ademais, segundo os autores, a atividade foi capaz de auxiliar no comprometimento e na coletividade da turma, contribuindo para uma formação cidadã. Entretanto, apesar dos benefícios evidenciados no uso de paródias, as atividades que envolvem a Música e as outras formas de Arte devem ser utilizadas de forma complementar e não substituir os processos de aprendizagem já existentes (MENDONÇA; LEITE, 2010).

Nessa revisão, também encontramos uma grande quantidade de publicações relacionadas à análise de letras de músicas, que em sua maioria tiveram como objetivo ressaltar os conteúdos presentes nas composições. A publicação número 1 (quadro 1) abordou a temática do desequilíbrio ambiental por meio das letras das músicas "A Serra", da Plebe Rude, e "Passaredo", de Chico Buarque e Francis Hime. Na publicação número 2 (quadro 1), os autores ressaltaram o fenômeno da reflexão da luz nos sambas "Além do espelho", de João Nogueira e Paulo César, e "A deusa da minha rua", de Newton Teixeira e Jorge Faraj. O trabalho número 
8 (quadro 1) utilizou as canções "Lance de dados", "Nem +1 dia", "Luz" e "Quase uma oração", de Humberto Gessinger, para abordar questões submicroscópicas. No artigo número 14 (quadro 1), os autores apresentaram músicas aos estudantes cujas inspirações foram a lua. Para tanto, utilizaram as letras de "Walking on the moon", do trio inglês The Police, e "Tendo a lua", da banda brasileira Paralamas do Sucesso. A publicação número 30 (quadro 1) trabalhou diferentes aspectos de Ciência, Tecnologia e Sociedade por meio das obras de Chico Buarque.

Ao analisar a publicação número 7 (quadro 1), constatamos que a atividade foi além da mera análise das letras. Após selecionarem as músicas "A serra", da banda Plebe Rude, "Passaredo", de Chico Buarque, "O pulso", da banda Titãs, e "Água e Fogo", da banda Tribo, destacaram as informações do senso comum, as doenças, os micro-organismos e os aspectos sociais e culturais. Os estudantes e o docente desenvolveram uma web-rádio onde compartilharam as informações obtidas com a sociedade a partir de um link na internet. A atividade contou com a participação de 500 internautas, promovendo nos discentes uma conscientização e valorização da divulgação científica, como propõem Krasilchik e Marandino (2004) quando dizem que o processo de alfabetização científica deve ultrapassar os muros da escola.

\begin{abstract}
O processo de alfabetização em ciência é contínuo e transcende o período escolar, demandando aquisição permanente de novos conhecimentos. Escolas, museus, programas de rádio e televisão, revistas, jornais impressos devem se colocar como parceiros nessa empreitada de socializar o conhecimento científico de forma crítica para a população (KRASILCHIK; MARANDINO, 2004, p. 14).
\end{abstract}

De acordo com Oliveira, Rocha e Francisco (2008) as análises de letras de músicas são capazes de ultrapassar a tarefa de identificar os conteúdos nas letras quando bem orientadas. As análises em sala de aula possibilitam que os discentes estabeleçam correlações, ampliem seus conhecimentos gerais e promovam uma transformação pessoal. Logo, pode-se considerar que a Música também é um recurso pedagógico capaz de auxiliar a divulgação e popularização científica, ultrapassando a barreira da educação formal.

Nas publicações números 18 e 19 (quadro 1), os professores foram convidados a responder perguntas pré-definidas pelos pesquisadores. Na publicação número 19, os autores destacaram os conteúdos presentes na letra da música "Tico-tico no fubá", de Zequinha de Abreu, e criaram uma proposta didática com perguntas que posteriormente pode ser utilizada por docentes em suas práticas educativas. Fato semelhante ocorreu na publicação número 18, em que os autores elaboraram uma estratégia pedagógica com 16 perguntas sobre conteúdos das disciplinas de Ciências e Biologia presentes na letra da música “Aqui no mar”, de Diogo 
Nogueira. Ambas publicações tiveram como objetivo fornecer uma atividade escolar já pronta, com perguntas previamente definidas, a fim de auxiliar os docentes e facilitar a compreensão de conceitos científicos.

Os resultados obtidos nesta revisão integrativa sobre o uso da Música no ensino evidenciaram que essa forma de Arte pode servir como recurso didático interdisciplinar e ser aplicada em aulas de diferentes faixas etárias e níveis de escolaridade. A Música é capaz de interagir com diversos conteúdos, favorecendo o processo de ensino e aprendizagem. No entanto, alguns trabalhos utilizaram a Música de forma secundária, sem a preocupação de desenvolver seus conteúdos e conceitos, contrariando o significado de interdisciplinaridade. A abordagem interdisciplinar necessita de um ponto de cruzamento entre duas ou mais áreas de conhecimento, em que todas são desenvolvidas (LEIS, 2015).

Salientamos que, ao relacionar a Música com os conteúdos, na sala de aula, o docente em parte rompe com o "modelo bancário tradicional", pois a Música pode ser um caminho pedagógico para a construção de indivíduos críticos e reflexivos. Pode aproximar os conteúdos da matriz curricular à realidade do educando, pois é construída dentro de um contexto histórico e cultural. Permite a partilha de emoções e afetos, podendo fortalecer as relações humanas (AREIAS, 2016).

No processo de ensino e aprendizagem, as relações docente-discentes e discentesdiscentes são negligenciadas na maioria das vezes. Segundo Vygotsky (1988), todo aprendizado resulta em desenvolvimento mental e a função da escola é promover tal desenvolvimento. $\mathrm{O}$ ambiente escolar tem um papel preponderante no desenvolvimento cognitivo, pois os conhecimentos se constroem na dinâmica das relações sociais. Ademais, Wallom (1989) nos alerta para um desenvolvimento intelectual mais humanizado, que considera o indivíduo como um todo, ou seja, afetividade, emoções, movimento e espaço físico se encontram num mesmo plano. A Música pode favorecer esse processo porque, em geral, promove aulas mais participativas, inclusivas e reflexivas, despertando o interesse dos discentes, tornando o aprendizado mais significativo.

No nosso estudo, também verificamos que alguns autores associaram a Música a outras formas de Arte, como o Cinema, Fotografia, História em Quadrinhos, Literatura, Teatro, Pintura e Escultura. O que demonstra o reconhecimento da importância das Artes no processo transdisciplinar, integrado e não fragmentado de ensino.

Contudo, é importante ressaltar que os resultados positivos estão sempre alinhados a um bom planejamento. Os docentes precisam preparar a aula de acordo com as peculiaridades da 
turma e dos objetivos que se deseja alcançar. Um olhar crítico sobre a obra musical que será utilizada é fundamental para que possa ser ouvida, cantada e sentida plenamente e resulte na construção de novos conhecimentos.

\section{CONSIDERaÇões Finais}

O presente estudo procurou por meio de uma revisão integrativa analisar como a Música vem sendo utilizada no ensino de Ciências e Saúde, a fim de entender o seu potencial na área de ensino. A Música faz parte da história da humanidade e, graças a Pitágoras, está presente na matriz curricular desde a Antiguidade. No decorrer dos séculos, as mudanças na educação distanciaram as Artes do ensino, o fragmentaram e o descontextualizaram nos seus diferentes níveis com a criação do sistema de disciplinas. Entretanto, uma nova sociedade com base nas Tecnologias da Informação e Comunicação provocou várias mudanças que exigem a formação de um cidadão crítico, sensível, autônomo e criativo, capaz de fazer conexões e propor soluções. Nesse contexto, o retorno das Artes à matriz escolar, de forma integrativa e interdisciplinar, pode favorecer a formação desse novo perfil de cidadão. Dentre as Artes temos a Música, que pode sensibilizar os estudantes, contextualizar os conteúdos e estimular o desenvolvimento de uma postura crítica diante dos problemas sociais, políticos, econômicos e culturais de sua realidade social.

Nas publicações analisadas, identificamos diversas formas de se empregar a Música. Vários docentes se apropriaram dessa Arte para promover um novo olhar e reflexões em diferentes níveis de ensino, da educação básica ao ensino superior. Os resultados revelaram que a Música torna as aulas mais participativas, reflexivas e inclusivas e aumenta o interesse dos educandos pelo componente curricular. No entanto, salientamos que a Música, por si só, não tem o poder de transformar a realidade educacional brasileira, que, apesar da recente reforma, precisa ser reavaliada para responder às necessidades da sociedade vigente. Mas a Música renova a sala de aula e não podemos viver no século XXI formando cidadãos como fazíamos no século XIX, uma vez que o principal papel da escola é formar o cidadão para a sociedade em que vive.

\section{REFERÊNCIAS}

ALBUQUERQUE, Eduardo da Motta; SIMÕES, Rodrigo; BAESSA, Adriano;

CAMPOLINA, Bernardo; SILVA, Leandro. A Distribuição Espacial da Produção Científica e Tecnológica Brasileira: uma descrição de estatísticas de produção local de patentes e artigos 
científicos. Revista Brasileira de Inovação, v. 1, n. 2, p. 225-251, 2002. Disponível em: https://doi.org/10.20396/rbi.v1i2.8648860. Acesso em: 12 de maio 2020.

ARAÚJO, Debora Cristina; MOTTA, Alexandre Negreiros; LIMA, Renato Abreu. O uso da música como auxílio no processo de aprendizagem: um recurso pedagógico. South American Journal of Basic Education, Technical and Technological, v. 4, n. 1, p. 263-269, 2017. Disponível em: https://periodicos.ufac.br/index.php/SAJEBTT/article/view/1161/791. Acesso em: 12 de maio 2020.

ARAÚJO, João Paulo Pereira; JÚNIOR, José Geraldo Ribeiro. Plataforma Matematech: um recurso didático no ensino de matemática nos anos iniciais do Ensino Fundamental.

Informática na educação: teoria \& prática, v. 20 n. 2, p. 17-35, 2017. Disponível em: https://doi.org/10.22456/1982-1654.63769. Acesso em: 12 de maio 2020.

AREIAS, José Carlos. A música, a saúde e o bem estar. Porto Mar: Nascer e Crescer, 2016.

BARBOSA, Ana Mae. A Imagem no Ensino da Arte. São Paulo: Perspectiva, 2014.

BERTONCELLO, Ludhiana; SANTOS, Marcio Rogério. Música aplicada ao ensino da informática em ensino profissionalizante. Iniciação Científica CESUMAR, v.4, n. 2, p. 131$142,2002$.

BRANDÃO, Lucas Esquivel Dias; BARROS, Marcelo Diniz Monteiro. A utilização da música "Aqui no Mar" como estratégia pedagógica para o ensino de ciências e biologia. Revista europeia de estudos artísticos, v. 7 n.1 p. 1-20, 2016.

BRASIL. Parâmetros Curriculares nacionais. Introdução. Ensino Fundamental. Brasília: MEC/SEF, 1998.

BRASIL. Novo Ensino Médio - perguntas e respostas. Portal do Ministério da Educação, 2020. Disponível em: http://portal.mec.gov.br/component/\%20content/article?id=40361. Acesso em: 12 maio 2020.

DECCACHE-MAIA, Eline; MESSEDER, Jorge Cardoso. O uso da arte como narrativa na abordagem CTS no ensino de ciências. Indagatio Didactica, v. 8, n. 1, p. 571-583, 2016. Disponível em: https://proa.ua.pt/index.php/id/article/view/3370/2650. Acesso em: 12 maio 2020.

DELIZOICOV, Demetrio; ANGOTTI, José Andre; PERNAMBUCO, Marta Maria. Ensino de Ciências: fundamentos e métodos. 3. ed. São Paulo: Cortez, 2002.

DELIZOICOV, Demetrio; SLONGO, Iône Ines Pinsson; LORENZETTI, Leonir. Um panorama da pesquisa em educação em ciências desenvolvida no Brasil de 1997 a 2005.

Enseñanza de las Ciencias, v. 12, n. 3 p. 459-480, 2013. Disponível em:

http://reec.webs.uvigo.es/volumenes/volumen12/REEC_12_3_5_ex718.pdf. Acesso em: 12 maio 2020.

DELORS, Jacques. Educação: um tesouro a descobrir. Relatório para a UNESCO da Comissão Internacional sobre Educação para o século XXI. São Paulo: Cortez Editora, 2010. 
DINIZ, Clélio Campolina; VIEIRA, Danilo Jorge. Ensino Superior e Desigualdades Regionais: notas sobre a experiência recente do Brasil. Revista Paranaense de Desenvolvimento, v. 36, n. 129, p. 99-115, 2015.

DURAND, Gilbert. Multidisciplinarités et heuristique. In: PORTELLA E. (Org.). Entre savoirs: l'interdisciplinarité en actes: enjeux, obstacles, résultats. Toulouse:

Érès/Unesco,1991.

FERREIRA, Luiz Henrique; HARTWIG, Dácio Rodney. Experimentação. In: I ENCONTRO PAULISTA DE PESQUISA EM ENSINO DE QUÍMICA, 2004, São Paulo. Anais... São Paulo, 2004.

FREIRE, Paulo. Pedagogia do Oprimido. 58. ed. Rio de Janeiro: Paz e Terra, 2014.

IAZZETA, Fernando. O que é a música (hoje). In: I FÓRUM CATARINENSE DE MUSICOTERAPIA. Florianópolis, Brasil. Anais...Florianópolis, 2001.

KARAT, Marinilde Tadeu. Contribuições da epistemologia e da análise de discurso para o ensino dos resíduos sólidos. In: VI ENCONTRO REGIONAL SUL DE ENSINO DE BIOLOGIA, XVI SEMANA ACADÊMICA DE CIÊNCIAS BIOLÓGICAS. Anais... Rio Grande do Sul, 2013.

KRASILCHIK, Myriam. O professor e o currículo das ciências. São Paulo: E.P.U., 2012.

KRASILCHIK, Myriam. Prática de ensino de Biologia. 4. ed. São Paulo, EDUSP, 2008.

KRASILCHIK, Myriam; MARANDINO, Martha. Ensino de ciências e cidadania. São Paulo: Moderna, 2004.

LEIS, Héctor Ricardo. Sobre o conceito de interdisciplinaridade. Revista

Interdisciplinaridade, n. 6, p. 1-23, 2015. Disponível em:

https://periodicos.ufsc.br/index.php/cadernosdepesquisa/article/view/2176/4455. Acesso em: 24 de agosto de 2020.

LIPPE, Eliza Márcia Oliveira; BASTOS, Fernando. Formação inicial de professores em biologia: fatores que influenciam o interesse pela carreira do magistério. In: BASTOS, Fernando; NARDI, Roberto. Formação de professores e práticas pedagógicas no ensino de ciências: contribuições da pesquisa na área. São Paulo: Escritura Editora, 2008.

MENDES, Karina Dal Sasso; SILVEIRA, Renata Cristina de Campos Pereira; GALVÃO, Cristina Maria. Revisão integrativa: método de pesquisa para a incorporação de evidências na saúde e na enfermagem. Texto \& Contexto - Enfermagem, v. 17, n. 4, p. 758-764, 2008. Disponível em: https://doi.org/10.1590/S0104-07072008000400018. Acesso em: 12 maio 2020.

MENDONÇA, Lêda Glicério; LEITE, Sidnei Quezada Meireles. Artes cênicas no ensino de boas práticas de fabricação: uma prática pedagógica no curso superior de Química. Revista Electrónica de Enseñanza de las Ciencias, v. 9, n. 1, p. 53-66, 2010. Disponível em: http://reec.uvigo.es/volumenes/volumen9/ART4_VOL9_N1.pdf. Acesso em: 12 maio 2020. 
MORÁN, José. Mudando a educação com metodologias ativas. Coleção Mídias Contemporâneas. Convergências Midiáticas, Educação e Cidadania: aproximações jovens, v. 2, 2015. Disponível em: http://www2.eca.usp.br/moran/wpcontent/uploads/2013/12/mudando_moran.pdf. Acesso em: 12 maio 2020.

MOREL, Regina Lúcia de Moraes; MOREL, Carlos Médici. Um estudo sobre a produção científica brasileira, segundo os dados do Institute for Scientific Information (ISI). Ciência da Informação, v. 6. n. 2, p. 99- 109, 1977. Disponível em:

http://revista.ibict.br/ciinf/article/view/85. Acesso em: 12 maio 2020.

NACARATO, Adair Mendes. A parceria universidade-escola: utopia ou possibilidade de formação continuada no âmbito das políticas públicas? Revista Brasileira de Educação, v. 21, n. 66 p. 699-716, 2016. Disponível em: https://doi.org/10.1590/S1413-24782016216636. Acesso em: 12 maio 2020.

NJAINE, Kathie; MINAYO, Maria Cecília de Souza. Violência na escola: identificando pistas para a prevenção. Interface - Comunicação, Saúde, Educação, v.7, n. 13 p.119-34, 2003. Disponível em: https://doi.org/10.1590/S1414-32832003000200009. Acesso em: 12 maio 2020.

OLIVEIRA, Adriane Dall'Acqua de; ROCHA, Dalva Cassie; FRANCISCO, Antônio Carlos de. A ciência cantada: um meio de popularização da ciência e um recurso de aprendizagem no processo educacional. In: SEMINÁRIO NACIONAL DE EDUCAÇÃO PROFISSIONAL E TECNOLÓGICA. Anais... Belo Horizonte, 2008.

ROOT-BERNSTEIN, Bob; SILER, Todd; BROWN, Adam; SNELSON Kenneth. ArtScience: integrative collaboration to create a sustainable future. Leonardo, v. 44, n. 3, p. 192, 2011. Disponível em: https://doi.org/10.1162/LEON_e_00161. Acesso em: 12 maio 2020.

SILVA, Monica Ribeiro. Direito à educação, universalização e qualidade: cenários da Educação Básica e da particularidade do Ensino Médio. Jornal de Políticas Educacionais, v. 9, n. 17, p. 61-74, 2015. Disponível em: http://dx.doi.org/10.5380/jpe.v9i17/18.41441. Acesso em: 12 maio 2020.

SILVA-PIRES, Felipe do Espirito Santo; CARVALHO, Anna Cristina Calçada; VASCONCELLOS-SILVA, Paulo Roberto; TRAJANO, Valéria da Silva. Imagens artísticas nos livros didáticos e o seu potencial transdisciplinar no ensino. Em Aberto, v. 31, n. 103, p. 79-105, 2018. Disponível em: https://doi.org/10.24109/2176-6673.emaberto.31i103.4018. Acesso em: 12 maio 2020.

SIMON, Eduardo; JEZINE, Edineide; VASCONCELOS, Eymard Mourão; RIBEIRO, Katia Suely Queiroz Silva. Metodologias ativas de ensino-aprendizagem e educação popular: encontros e desencontros no contexto da formação dos profissionais de saúde. Interface Comunicação, Saúde, Educação, v. 18, n. 2, p. 1355-1364, 2014. Disponível em: https://doi.org/10.1590/1807-57622013.0477. Acesso em: 12 maio 2020.

SNYDERS, Georges. Alunos felizes: reflexão sobre a alegria na escola a partir de textos literários. São Paulo: Paz e Terra, 2005. 
SOUZA, Marcela Tavares de; SILVA, Michelly Dias da; CARVALHO, Rachel. Revisão integrativa: o que é e como fazer. Einstein, v. 8, p. 102-6, 2010. Disponível em: https://doi.org/10.1590/s1679-45082010rw1134. Acesso em: 12 maio 2020.

TEIXEIRA, Paulo Marcelo Marini; MEGID-NETO, Jorge. O estado da arte da pesquisa em ensino de Biologia no Brasil: um panorama baseado na análise de dissertações e teses.

Enseñanza de las Ciencias, v. 11, n. 2, p. 273-297, 2012. Disponível em: http://reec.uvigo.es/volumenes/volumen11/REEC_11_2_2_ex500.pdf. Acesso em: 12 maio 2020 .

THEODORO, Flávia Cristine Medeiros; COSTA, Josenilde Bezerra de Souza; ALMEIDA, Lucia Maria de. Modalidades e recursos didáticos mais utilizados no ensino de Ciências e Biologia. Estação Científica UNIFAP, v. 5, n. 1, p. 127-139, 2015. Disponível em: https://periodicos.unifap.br/index.php/estacao/article/view/1724. Acesso em: 12 maio 2020.

TRAJANO, Valéria da Silva; MENDES, Marcelo Oliveira; AZEVEDO, Sandra Maria Gomes; MATRACA, Marcus Vinicius Campos; D’ANDREA, Paulo Sergio; CARVALHO, Anna Cristina Calçada; ARAÚJO-JORGE, Tania Cremonini. Expedições por um brasil sem miséria - oficinas de ecoarte - um relato de experiência. Revista Ciências \& Ideias, v. 8, n. 3, p. 116-130, 2018. Disponível em: http://dx.doi.org/10.22407/2176-1477/2017.v8i3.706. Acesso em: 12 maio 2020.

VILLAÇA, Iara de Carvalho. Arte-educação: a arte como metodologia educativa. Cairu em revista, v. 3, n. 4, p. 74-85, 2014. Disponível em:

https://www.cairu.br/revista/arquivos/artigos/2014_2/05_ARTE_EDUCACAO_METODOLO GIA_EDUCATIVA.pdf. Acesso em: 12 maio 2020.

VYGOTSKY, Lev Semyonovich. A formação social da mente: o desenvolvimento dos processos psicológicos superiores. São Paulo: Martins Fontes, 1998.

WALLON, Henri. As Origens do pensamento na criança. São Paulo: Manole, 1989.

Recebido em: 14 de maio de 2020.

Aprovado em: 30 de agosto de 2020. 